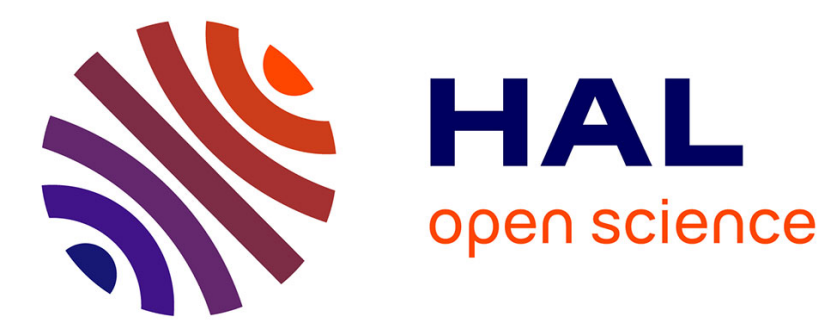

\title{
A study on the interaction between local flow and flame structure for mixing-controlled Diesel sprays
}

José M García-Oliver, Louis-Marie M Malbec, Hubert M Baya Toda, Gilles M Bruneaux

\section{- To cite this version:}

José M García-Oliver, Louis-Marie M Malbec, Hubert M Baya Toda, Gilles M Bruneaux. A study on the interaction between local flow and flame structure for mixing-controlled Diesel sprays. Combustion and Flame, 2017, 179, pp.157 - 171. 10.1016/j.combustflame.2017.01.023 . hal-01566130

\section{HAL Id: hal-01566130 \\ https: / hal-ifp.archives-ouvertes.fr/hal-01566130}

Submitted on 20 Jul 2017

HAL is a multi-disciplinary open access archive for the deposit and dissemination of scientific research documents, whether they are published or not. The documents may come from teaching and research institutions in France or abroad, or from public or private research centers.
L'archive ouverte pluridisciplinaire HAL, est destinée au dépôt et à la diffusion de documents scientifiques de niveau recherche, publiés ou non, émanant des établissements d'enseignement et de recherche français ou étrangers, des laboratoires publics ou privés. 


\title{
A study on the interaction between local flow and flame structure for mixing- controlled Diesel sprays
}

José M. García-Oliver ${ }^{\mathrm{a}}$, Louis-Marie Malbec ${ }^{\mathrm{b}}$, Hubert Baya Toda ${ }^{\mathrm{b}}$, Gilles Bruneaux ${ }^{\mathrm{b}}$

a CMT-Motores Térmicos - Universitat Politècnica de València, Camino de Vera s/n,46022,Valencia,Spain

b IFP Energies nouvelles, 92852 Rueil-Malmaison Cedex, France; Institut Carnot IFPEN Transports Energie

\begin{abstract}
A detailed study on the spray local flow and flame structure has been performed by means of PIV and laser-sheet LIF techniques under Diesel spray conditions. Operating conditions were based on Engine Combustion Network recommendations. A consistent comparison of inert and reacting axial velocity fields has produced quantitative information on the effect of heat release on the local flow. Local axial velocity has been shown to increase 50 to $60 \%$ compared to the inert case, while the combustion-induced radial expansion of the spray has been quantified in terms of a 0.9 to $2.1 \mathrm{~mm}$ radius increase. As a result, the drop in entrainment rate has been quantified around $25 \%$ compared to the inert case. Streamline analysis also hints at a reduced entrainment under reacting conditions. A 1D spray model under reacting condition has been used, which confirms the modifications obtained in the main flow metrics when moving from inert to reacting conditions. When comparing the flow evolution with the flame structure, little effect of chemical activity on the spray flow upstream the lift-off length has been evidenced, in spite of the presence of formaldehyde in such regions. Only downstream of the lift-off length, as defined by OH LIF, has a strong change in flow pattern been observed as a result of combustion-induced heat release.
\end{abstract}

\section{KEYWORDS}

Diesel flame - Velocity - Entrainment - Reactive Flow

\section{INTRODUCTION}

Driven by the need to comply with engine-out emission regulations, last two decades have seen a huge development of the fundamental knowledge related to Diesel spray combustion. Initial efforts were mainly based upon experimental investigations, which enabled the synthesis of conceptual models [1]-[3] that contained a description of physical and chemical processes taking place during the different stages of the spray evolution. The development of computational models capable of predicting such fundamental processes has been a second major achievement in this scientific field, which can lead to an improved engine design [4]. In the meantime, the synergy between modelling and experiments is leading to an improved understanding of such complex phenomena, as recent activities within the Engine Combustion Network (ECN) demonstrate [5].

Most of the efforts within this field have been devoted to the understanding of the mixing process between fuel and air, which governs Diesel combustion process. Experimental investigations have delivered spray tip penetration [6], [7], mixture fraction [7] and local velocity measurements [8][9], which have led to the general conclusion that the mixing process of a Diesel spray is rather similar to that of a gas jet at similar mass momentum and fuel/air density ratio conditions [10]. On the other hand, knowledge on the interaction between mixing process and flame development is a more open topic, where some questions are still unresolved. As an example, lift-off length has been within the scope of many analyses, which have been very often based upon the experimental quantification of this characteristic length [11]-[13]. The mechanism governing lift-off stabilisation is still not fully explained, with 
different hypotheses still under discussion, e.g the stabilization location at equilibrium between the local flow and combustion velocity or the recirculation of burnt gases at the flame base, among others [14], [15]. This characteristic length is also a point of interaction between the mixing field and flame development, with important consequences on soot production as correlations between equivalence ratio at the lift-off length and soot measurements within the flame have shown [12].

Keeping the previous framework in mind, some still unknown issues on the evolution of Diesel sprays can be identified, which mainly have to do with the spray flow development. The latter topic has been deeply analysed in terms of spray tip penetration and, to a much lower extent, with local velocity measurements [8], [9], [16]. However, except for the classical work by Kobayashi [17] using shadowgraph visualization and a more recent one by Farrell [16] using PIV, most of such studies have been usually carried out under inert spray conditions. Furthermore, only the latter authors report a detailed comparison between inert and reacting conditions. More systematic approaches have been found recently on the evolution of the spray flow after heat release onset. Evidences have been mainly based on high speed schlieren imaging, which has shown that the evolution of the spray tip penetration departs from the inert one due to heat release [17]-[21]. The magnitude of the change depends on the operating conditions, ranging from no effect on heat release [20] to a clear acceleration of reacting versus inert penetration [19], [21]. Furthermore, an increase in spray width due to heat release has also been quantified [22]. Although most of such phenomena happen during the main injection period, flow effects have also been deeply investigated in the afterend-of-injection phase [9][23][24], due to their implications on late combustion and unburnt hydrocarbon formation.

The immediate question is therefore how the reacting flowfield interacts with the flame structure. A first example has already been discussed above, namely the flame lift-off stabilization, although many other are possible, which make up the natural framework for the present contribution. The work reported here has two general objectives. On the one hand, a detailed description of the changes in local flow evolution when shifting from inert to reacting conditions will be carried out by means of PIV measurements. The second major point of analysis will be the interaction between the local flow and the flame structure, for which the PIV results will be compared to those obtained by means of LIF techniques. In both cases, the analysis will be based upon ECN collaborative results [5], which have made it possible to build a detailed database of Diesel spray behaviour under inert and reacting conditions, for both local flow evolution and flame metrics. Only the availability of such detailed information will help answer such fundamental questions.

\section{METHODOLOGY}

\subsection{Experimental conditions}

Experiments have been conducted at IFPEN constant-volume pre-burn vessel, which simulates thermodynamic conditions near top-dead-center in a compression-ignition engine [25]. The interior of the optical chamber is a cube, $1.4 \mathrm{~L}$ in volume, with windows in the cube faces for laser and imaging access. Within the vessel, high ambient temperatures are achieved through the combustion of a flammable gas mixture. The injection is triggered when the desired chamber temperature is reached during the cool-down of the combustion products. Initial pressure and composition (before the combustion event) are selected to obtain the desired temperature, density, and oxygen concentration at the start of injection (see [25] for more details on the vessel operation). Three experimental conditions have been considered in the present study, which are described in Table 1. The first one corresponds to the nominal ECN Spray A (SA) condition, while the other two imply a modification in ambient temperature (T2) and temperature and density (EX) compared to SA. Experimental data have been obtained in three different campaigns:

- $\quad$ A first PIV campaign, producing Spray A (inert/reacting) PIV data ( $2^{\text {nd }}$ ECN Workshop).

- A second PIV campaign, producing T2 and EX PIV data ( $3^{\text {rd }}$ ECN Workshop).

- A LIF/OH* campaign, producing SA, T2 and EX LIF data ( $3^{\text {rd }}$ ECN Workshop). 
PIV for SA condition (inert and reacting) and T2 (inert) have been published in [9], [26], respectively, although a detailed analysis of entrainment under reacting conditions has not been performed before. LIF/OH* results for SA have been published in [27], and the remaining conditions are analysed here for the first time.

A single-hole Bosch injector (reference units \#210678 and 201-02) from the Engine Combustion Network has been used. Fuel pressure is controlled with a pneumatic pump, and the fuel is provided through a common rail, following ECN recommendations (Picket et. al. 2010). The fuel is n-dodecane, which has a density of $703 \mathrm{~kg} / \mathrm{m}^{3}$ at the experimental conditions. The fuel pressure is set at $1500 \mathrm{bar}$, for which the steady-state average mass flux through the injector is $2.25 \mathrm{~g} / \mathrm{s}$ and the corresponding momentum flux is $1.22 \mathrm{~N}$. The nozzle has a $88.6 \mu \mathrm{m}$ orifice diameter. Injection duration has been long for all experiments ( $5000 \mu \mathrm{s})$ to enable the analysis of the steady flow and flame structure, except for the PIV measurements under SA condition, for which the ECN standard $1500 \mu$ s injection duration has been used.

Based upon the previous operating conditions, some combustion metrics have been obtained that can help identify the general combustion evolution, namely ignition delay (ID), $\mathrm{OH}^{*}$ derived lift-off length (OH* $\mathrm{LOL}$ ) and an estimation of the equivalence ratio on the spray centerline at the LOL $\left(\phi_{\mathrm{c}, L, L L}\right)$ by means of the 1D spray model referenced below. Such quantitative parameters are included in Table 2, together with the equivalent diameter $d_{e q}=d_{0} \sqrt{\frac{\rho_{f}}{\rho_{a}}}$ according to the classic definition in the literature [28], [29], which will be later used to normalize analysis under different entrainment conditions.

\subsection{Experimental tools}

\subsubsection{PIV measurements}

A schematic of the optical setup for PIV measurements is shown in Figure 1 (left). The ambient into which injection occurs is seeded with zirconium oxide particles with a diameter below $5 \mu \mathrm{m}$, density $5700 \mathrm{~kg} / \mathrm{m}^{3}$. The estimated Stokes number is below 0.2 in the measurement region. Illumination is provided by a double-pulsed two-cavity 527 $\mathrm{nm}$ YLF laser. Each laser cavity is operated at $10 \mathrm{kHz}$. A $1 \mathrm{~mm}$ thick, $64 \mathrm{~mm}$ wide horizontal laser sheet is formed by the combination of spherical and cylindrical lenses, and intercepts the spray axis horizontally, in the focal plane of the camera. The time delay between consecutive pulses from the two laser cavities is $2 \mu \mathrm{s}$, whereas $100 \mu \mathrm{s}$ elapses between 2 pulses from the same laser cavity. Therefore two velocity fields can be derived:

- Using the long pulse separation, the flow outside the spray will be quantified.

- The short pulse separation will be used to quantify local velocities inside the spray.

A Photron SA1 high-speed camera equipped with a Nikkor $50 \mathrm{~mm} f / 1.2$ lens and an $8 \mathrm{~mm}$ extension ring collects the Mie-scattered laser light off the particles. The camera acquires images at $20 \mathrm{kHz}$ with an exposure time of $50 \mu \mathrm{s}$. Since subsequent pulses from the same cavity are used here, the effective acquisition rate is $10 \mathrm{kHz}$. The size of each image is $448 \times 592$ pixels, with a resolution of 8 pixels per $\mathrm{mm}$ [ $56 \times 74 \mathrm{~mm}$ ]. An example image is shown in Figure 1 (right), $1700 \mu$ s after the commanded start of injection.

LaVision suite (DaVis 8) is used for processing the raw images. A multi-pass windowing procedure computes correlations at $64 \times 64$ pixels followed by $16 \times 16$ pixels and good vectors are selected using median filtering. Outside the spray, the procedure yields in excess of $95 \%$ good vectors. To obtain statistically meaningful ensemble velocity fields, 40 injections are averaged in the data presented here.

A system of cylindrical coordinates is adopted for analysis, centered on the nozzle tip. For the image in Figure 1 (right), the injector tip is $7 \mathrm{~mm}$ outside the field of view, and the jet propagates downward along the centerline $(r=0)$ in this perspective. The top $14 \mathrm{~mm}$ of the field of view is not illuminated by the laser sheet (though stray reflections make the spray visible in this region). The reported PIV data exist between $21 \mathrm{~mm}$ and $80 \mathrm{~mm}$ downstream of nozzle orifice. 


\subsubsection{LIF measurements}

PLIF was used to detect products of both high- and low-temperature reactions under investigated conditions. A detailed description of the methodology can be found in [27]. In order to probe the ground state $\mathrm{OH}$ radicals, a frequency-doubled dye laser operated on Rhodamine $6 \mathrm{G}$ was used, which was pumped using a frequency-doubled $\mathrm{Nd}$ :YAG laser at $532 \mathrm{~nm}$. Excitation was induced at a wavelength of $282.92 \mathrm{~nm}$, corresponding to the Q1(6) transition. An off-resonance correction was used for the obtained results by tuning the dye laser to a wavelength of $283.10 \mathrm{~nm}$. A $18 \mathrm{~mm} \times 0.5 \mathrm{~mm}$ laser sheet was formed for each laser shot, and two images with an adjacent laser sheet location were combined for each experimental condition to achieve a field of view of about $35 \mathrm{~mm}$. The detection of $\mathrm{OH}$ PLIF was achieved using an intensified CCD camera (Princeton Instruments, PI-MAX2, RB slow photocathode) equipped with a Sodern lens (CERCO $45.5 \mathrm{~mm} \mathrm{f} / 1.8$ ) and a Semrock band-pass filter set centered at $315 \mathrm{~nm}$ (25nm FWHM). A 50ns exposure time was used. The resolution is 10 pixels $/ \mathrm{mm}$. For $355 \mathrm{~nm}$ PLIF, the extent of the laser sheet is 0 to $55 \mathrm{~mm}$ from the nozzle. For OH LIF, the axial extent of the laser sheet is $40 \mathrm{~mm}$, starting at $20 \mathrm{~mm}$ (SA and T2) and $40 \mathrm{~mm}$ (EX) from the nozzle. The thickness of the laser sheet in both cases is $0.5 \mathrm{~mm}$.

On the other hand, fluorescence from the vibronic bands of formaldehyde has been imaged using the third harmonic output of a Nd:YAG laser at $355 \mathrm{~nm}$ for excitation. The laser sheet size was $45 \mathrm{~mm} \times 0.5 \mathrm{~mm}$ at $100 \mathrm{~mJ} /$ pulse A Princeton Instruments, PI-MAX3 with a Sodern lens (CERCO $45.5 \mathrm{~mm}$ f/1.8), a band-pass filter at $474 \mathrm{~nm}(80 \mathrm{~nm}$ FWHM) and a gate time of 50 ns were used for the detection of formaldehyde. These experiments were conducted simultaneously with the OH PLIF ones. No correction for non-homogeneities in the laser sheet have been performed when processing LIF signals.

\subsection{3 $\mathrm{OH}^{*}$ chemiluminescence imaging}

Flame $\mathrm{OH}^{*}$ chemiluminiscence was imaged to quantify the lift-off length location. The same imaging setup (camera and lens) as in LIF measurements was used, equipped with a Semrock band-pass filter centered around $315 \mathrm{~nm}$. Images of the quasi-steady flame phase were acquired with a $2500 \mu$ s exposure time. Standardized processing routines from ECN [5] were used to derive the flame lift-off values recorded in Table 2. Furthermore, contours of the $\mathrm{OH}^{*}$ radiation will be use to analyse flame structure.

\subsection{Numerical tools}

A previously existing 1D spray model [30]-[32] has been used to backup the analysis of experimental results. The model solves 1D conservation equations of axial momentum and mixture fraction in terms of the axial distance to the nozzle. Radial dispersion is considered in the model by means of radial integral terms that assume a Gaussian self-similar profile. The model has been successfully used to predict inert spray penetration and liquid length [31], [32]. Compared to similar models in the literature, where density is assumed to be radially homogeneous [33], [34] and is not always coupled into the momentum equations [34], the present approach feeds local density decrease into conservation equations from the radial distribution of mixture fraction. For this purpose, state relationships are tabulated in terms of the mixture fraction for a given pressure, fuel and air temperature and composition. This approach enables the quantification of local heat release effects into the velocity distribution.

Under inert conditions, inputs for the model are

- Nozzle mass and momentum fluxes,

- Fuel temperature and density

- Ambient gas pressure, temperature and density

- Spray cone angle

When dealing with reacting conditions, a simplified single-step Burke-Schuman approach is followed to calculate the state relationships. An example for the nominal SA condition is shown for temperature and density in Figure 2 for both inert and reacting cases. Compared to the typical adiabatic mixing behaviour in the inert case, where temperature ranges from the air to the fuel one, a peak temperature is obtained under reacting conditions at stoichiometric mixture fraction $\left(f_{s t}=0.0406\right)$, consistently with the single-step chemistry assumption. In terms of density at stoichiometric conditions, this means a minimum value of around $9.0 \mathrm{~kg} / \mathrm{m}^{3}$ under reacting conditions compared to $25.5 \mathrm{~kg} / \mathrm{m}^{3}$ in the inert case, i.e. a density drop by a factor of 2.92 . 
Due to the absence of a chemical mechanism, two additional inputs for the model are

- Ignition delay $\left(t_{s o c}\right)$ to identify when combustion will start.

- On axis mixture fraction at the lift-off length $\left(f_{c l, L O L}\right)$, which will enable the model to spatially separate the locations where spray is inert and reacting. This is usually derived from the experimental lift-off length distance, and a model calculation under inert condition, which can be later converted to equivalence ratio at the lift-off length $\phi_{\mathrm{cl}, \text { Lol }}$ (Table 2). A detailed description is provided in the Appendix on the modelling approach to define the transition between the inert and reacting part of the spray at the lift-off length.

Finally, information on the combustion-induced radial expansion has to be fed in to the model to account for the experimentally observed radial dilation. Initially, this effect was accounted for by means of a so-called 'reacting spray cone angle' [30]. However, a more recent analysis of experimental information based on high speed schlieren imaging [22] has shown that the radial contour of a reacting spray is defined by a slope (i.e. cone angle) similar to the inert one, but with an increased width. According to that, the radial expansion of the reacting spray can be defined in terms of a radius increase $\Delta R$. PIV measurements also agree with this result, as subsequent analysis in the present paper will show. Therefore, this approach has also been included in the $1 \mathrm{D}$ model. To enable a quantitative prediction, it is assumed that, at start of combustion, the full available mass (fuel + air) downstream the lift-off length location undergoes a transition to reacting conditions (combustion products). Because of the drop in density, the spray expands, and in this process it is forced to increase at each cross-section from the initial inert limit $R_{\text {inert }}$ to a reacting one defined by $R_{\text {inert }}+\Delta R$, which is assumed to be the same for the whole burning zone. No additional inputs are therefore needed to model the radial dilation process.

For the calculations in the present work, nozzle-related parameters are taken from previous measurements by other groups [35], while ambient and fuel temperature and composition and ambient pressure are obtained from ECN specifications [5]. The spray cone angle has been used as to provide a reasonable inert spray evolution. For reacting conditions, the experimental ignition delay has been used, and the experimental flame lift-off length has been used to estimate the on-axis mixture fraction at the lift-off length, as explained before.

\section{ANALYSIS}

\subsection{Flow evolution}

Figure 3 (left column) shows the average profiles of on-axis velocity for several time instants and for all three investigated cases. For each condition, a reference profile under inert conditions has also been added. Starting from SA condition, velocity in the reacting cases can be observed to evolve with values above the initial inert state. Keeping in mind that ignition delay for SA is 410 us, one can observe that the development occurs in a quasi-steady manner, with velocity profiles progressively extending at the tip, while the velocity along the main part of the spray remains steady. Compared to the velocity of the reference inert case, on axis velocity values are up to $50 \%$ higher in the $\left[60 d_{\text {eq }}-90 d_{\text {eq }}\right]$ interval. The extent of the velocity field within the measurement window also evidences that the reacting spray penetrates faster than the inert one, in agreement with results in the literature for SA conditions [22].

For $\mathrm{T} 2$ and EX cases, the evolution is similar, with a progressive development of the reacting case at a higher velocity than the inert one. However, due to a delayed start of combustion as a result of the lower ambient temperature (Table 2), the timing of such development is also delayed. Two additional features can be observed:

- First, one can observe the initial part of the velocity profile under reacting conditions to overlap with the inert spray case until around $65 \mathrm{~d}_{\mathrm{eq}}$ for EX, and up to $50 \mathrm{~d}_{\mathrm{eq}}$ for T2. This means that heat release effect on the flow can only be observed downstream a particular location that, as will be shown later, is related to the flame lift-off length, as derived from $\mathrm{OH}^{*}$ visualization.

- Compared to SA, the magnitude of combustion-induced increase in velocity compared to the inert spray is around $60 \%$ for both T2 and EX, although in the latter case the reacting region occupies a small part within the measurement range, so this proportionality factor is not easy to estimate accurately.

Apart from the flow acceleration, heat release has been shown to induce a radial expansion of the spray [22], which can be evaluated here in terms of axial velocity field. Figure 3 (right column) shows the time evolution of spray velocity radius ( $5 \%$ of the on-axis value, noted $\mathrm{R} 5 \%$ ) with the same layout as for the on-axis velocity. This relatively 
high threshold value has been used to avoid that lowest velocity values within the spray drop below measurement uncertainty levels, which have been estimated considering 0.1 pixel uncertainty. This metrics indicates the width of the flow, therefore it can show when and where radial expansion due to combustion occurs. In this case, it is more convenient to start the discussion with the EX case, due to the longer injection period and extended lift-off length compared to the other two cases. The bottom plot shows how the inert profile overlaps with the reacting case until approximately 1000 us. Taking into account that the ignition delay is at $1190 \mu \mathrm{s}$ for this condition, heat release onset results in an abrupt increase in the radius starting quite repetitively at around $66 \mathrm{~d}_{\mathrm{eq}}$, i.e. a similar location as the onaxis velocity increase, which also corresponds to the position of the $\mathrm{OH}^{*}$-derived lift-off. The time evolution is also quasi-steady, in the sense that the spray mainly grows at the tip, while the upstream part is not largely modified with time.

For T2, some transition can be observed temporally for the first two instants, with the $701 \mu$ s plot being close to the fully inert velocity field, and the $1001 \mu \mathrm{s}$ already on the reacting evolution. Note that the ignition delay is $770 \mu \mathrm{s}$ for this operating condition. For SA, a similar behaviour is observed, but due to the short ignition delay (440 $\mu \mathrm{s})$, spray size is small, and most of the observable PIV field includes the highly transient spray tip. Therefore the inert to reacting transition is not easily observable. Furthermore, for SA condition injection end occurs at around $1500 \mu \mathrm{s}$, which means that the unsteady spray head accounts for a large part of the field of view during the whole injection event, compared to T2 or EX conditions, for which a steady evolution is observable, as the head vortex is out of the field of view. This is quite evident in the inert velocity at 1517 us, which seems to be wider than the reacting one at locations downstream $70 \mathrm{~d}_{\mathrm{eq}}$. However, under the previous limitations, one can still observe a region between 40 and $70 \mathrm{~d}_{\mathrm{eq}}$ where the combustion-induced radial expansion can be observed.

Based on high-speed schlieren imaging, Payri et al [22] concluded that the radial expansion in a reacting spray results in a contour that seems to be spatially shifted outwards in a constant increment compared to the inert one. The present contribution also indicates a similar result for the PIV-derived radius, which is quite evident for the latest time shown of both T2 and EX cases, while it can be guessed for the steady part of the SA case. A linear fit has been carried out for that time instant for both the inert and the reacting contours along the steady portion of the spray (Figure 3, right), from which the increase in radial width over the whole fitting interval can be quantified, as recorded in Table 3. The value shown here for the nominal SA $(0.70 \mathrm{~mm})$ is lower than the one by Payri et al [22] obtained from schlieren imaging $(\sim 1 \mathrm{~mm})$. However, additional considerations have to be made on this comparison. First, the measurement principle is quite different in both cases, so the same radius need not be necessarily obtained from both experimental techniques. On the other hand, the radius used for the definition of the spray limit is based upon a threshold value (5\%) which may be, as explained above, a conservative one to quantify the radius in a reliable way as from the experiments.

Apart from the local velocity values and the flow width, the hypothesis of self-similar axial velocity field development can be validated with the present results. For that purpose, the radial distribution of axial velocity in the quasisteady portion of the spray has been normalized by the on-axis value, and the radial coordinate has been normalized by the $5 \%$ radius, to account for the previously observed differences in flow width. This procedure has been applied to both inert and reacting cases. Figure 4 presents for all three cases the scatterplot of normalized velocity profiles for both inert and reacting conditions. A Gaussian profile has been included as a reference. Although scattering is visible in both inert and reacting cases, the hypothesis of self-similarity can be accepted under both flow situations, and the Gaussian function is a good approximation of the self-similar radial profile. This is an important results, since it validates the self-similarity hypothesis used in the 1D model, both in inert and reacting conditions. Furthermore, assuming that the Gaussian function fits the self-similar velocity profile, one can obtain a radius corresponding to the $1 \%$ limit in velocity from the $5 \%$ one, which is around $20 \%$ larger. Coming back to the previous analysis of the radial expansion, this has enabled the calculation of a 1\% Radius, as shown in Table 3. This would bring the PIV measured radial increase for nominal SA conditions from 0.70 to $0.87 \mathrm{~mm}$, i.e. closer to values obtained from schlieren by Payri et al [22].

\subsection{Flow versus flame structure}

The present section intends to present some of the features of the flame structure for the investigated conditions. Such information has been obtained only during the quasi-steady phase of the flame evolution, where the reacting 
spray grows mainly from the transient tip, while the remaining part does not change with time. Figure 5 shows the quasi-steady flame structure for all three conditions. Three sources of information are superimposed that describe the flame structure. On the one hand, red indicates zones where $\mathrm{OH}$ has been detected by PLIF technique, while green indicates zones where signal from the $355 \mathrm{~nm}$ PLIF technique is recorded, which can be due either to formaldehyde or to PAHs. On the other hand, the blue dotted line is the contour of the $\mathrm{OH}^{*}$ image, where the most upstream location should correspond to the LOL. For every map shown, the color scale is linear with the recorded digital level, and it has been intentionally saturated above $1 / 3$ of the maximum value of each case to focus on the spatial extent of the recorded signals.

For all three conditions, $355 \mathrm{~nm}$ PLIF signal in the vicinity of the nozzle exit is clearly due to light reflections on the liquid spray, as the typical narrow shape evidences. Another possible source is fluorescence of fuel impurities, which due to the high fuel concentration in that zone may be meaningful. Although the maximum liquid length cannot be observed from this experimental information, estimations from the 1D model indicate that this parameter should be 19, 25 and $29 \mathrm{~d}_{\mathrm{eq}}$ for SA, T2 and EX cases, respectively. This means that for all cases liquid length should be shorter than the minimum distances to the nozzle where heat release occurs. Downstream the liquid spray, the $355 \mathrm{~nm}$ PLIF signal appears at locations around 25, 30 and $35 \mathrm{~d}_{\mathrm{eq}}$ for conditions SA, T2 and EX, respectively, and it later spreads over the whole cross section, which most probably stems from the presence of formaldehyde due to low temperature autoignition chemistry. This extends until the location of $\mathrm{OH}^{*} \mathrm{LOL}$, consistently with several previous results [2], [36], [37], [27].

For the EX case, the low temperature zone of the flame is axially stretched, due to both the low temperature and the lower mixing rate (lower density) compared to the other two conditions, and a very active pool of formaldehyde extends from approximately 35 until $65 \mathrm{~d}_{\mathrm{eq}}$, just upstream the $\mathrm{OH}^{*} \mathrm{LOL}$ contour, where it drops in intensity. This location also coincides with the detection of the OH PLIF signal, which indicates the transition to the formation of a high temperature diffusion flame, with two lobes in the OH PLIF signal on both sides of the spray axis, which should be close to the location of the stoichiometric surface [38]. Previous results for SA condition [27] have shown that the location of the $\mathrm{OH}$ PLIF signal is spatially coincident with the presence of $\mathrm{OH}^{*}$ radiation. This is also the case for $\mathrm{T2}$ and EX. Further downstream, this overlap cannot be seen because of a drop in the the OH PLIF signal due to the lasersheet dimensions, which do not span the full spray region [27].

For the SA and T2 conditions, strong $355 \mathrm{~nm}$ PLIF signal is still observed downstream the OH*LOL location. In fact, for the SA condition the signal strength is much higher in those downstream locations, with OH PLIF and OH* contours enveloping the $355 \mathrm{~nm}$ PLIF signal. In this region close to the spray axis, however, chemistry has left the low temperature stages, consuming formaldehyde, and therefore the $355 \mathrm{~nm}$ PLIF signal will most probably stem from the presence of PAH which are excited by the selected wavelength [37], [39].

All in all, the appearing of $355 \mathrm{~nm}$ PLIF signal seems appears to be dependent on the operating conditions, in response to a change in temperature (approximately $5 \mathrm{~d}_{\text {eq }}$ longer when moving from SA to T2) and density (approximately $5 \mathrm{~d}_{\mathrm{eq}}$ longer when moving from T2 to EX). Note that in the latter case of density variation, the equivalent diameter is different (Table 3 ), so differences in actual spatial coordinates are even larger. On the other hand both the $\mathrm{OH}^{*}$ and the $\mathrm{OH}$ PLIF signals move downstream in response to the previous parametric variation, but the sensitivity is much higher (approximately $15 \mathrm{~d}_{\text {eq }}$ increase from SA to T2 and later to EX, respectively), i.e. high temperature chemistry is more strongly shifted away from the nozzle.

Figure 5 also shows the superposition of PIV-derived spray $1 \%$ radius on the previous flame information. The latter parameter has been presented for both the inert and reacting conditions to enable the identification of the locations where heat release begins to affect the flow. Starting from the closest location to the nozzle, formaldehyde can be found in the zone where both inert and reacting velocity contours overlap. This is especially evident for the EX condition, where a large part of the inert spray falls into the PIV measurement range. This indicates that the formation of formaldehyde does not bring about a quantitatively strong change in temperature/density, and therefore the flow structure is barely modified compared to the inert case.

The separation between the two PIV-derived radii (inert and reacting) occurs when the $\mathrm{OH}^{*}$ derived lift-off length location zone is reached, also coincident with the most upstream location of the OH LIF signal, where high temperature reactions occur and therefore the interaction of the heat release with the flow becomes evident. Both 
T2 and EX conditions clearly show this trend, while for SA this may not be as evident due to the short injection time for the PIV measurements, which prevented from obtaining a fully quasi-steady state picture. As a conclusion, the comparison of PIV flow under inert and reacting conditions can also help discern the location of the high temperature zone in the flame.

Finally, one can observe that in the vicinity of the $\mathrm{OH}^{*}$ lift-off length, the radial width of the flow as derived from axial velocity is essentially similar to that of the LIF measurements, whether from the 355 or from OH LIF. Only at isolated locations (e.g. around $70 \mathrm{~d}_{\text {eq }}$ for $\mathrm{T2}$, or $78 \mathrm{~d}_{\text {eq }}$ for EX) is the $\mathrm{OH}$ area wider than the spray flow width. Although the conclusion cannot be extended to locations farther away from the nozzle, and probably a deeper analysis is needed, this result hints at a similar diffusivity of mass and momentum, which is an important conclusion for CFD modelling comparison. On the other hand, the $\mathrm{OH}^{*}$ contour is always contained within the inert PIV radius. As $\mathrm{OH}^{*}$ species is located around stoichiometric conditions, this result is consistent with the fact that the small radial dilation effect does not expand the stoichiometric surface out of the inert spray contour.

\subsection{Discussion}

The previous sections have enabled the definition and quantification of flow-related metrics that have described the inert to reacting transition. Some trends already reported in the literature by means of schlieren imaging have been observed for the first time for Diesel sprays in terms of velocity-derived parameters:

- On the one hand, the transition from inert to reacting flow induces a velocity increase within the order of $50 \%$ for $\mathrm{SA}$, and $60 \%$ for $\mathrm{T} 2$ and $\mathrm{EX}$ for the steady part of the reacting spray.

- Furthermore, during the transition from inert to reacting spray, there is a radial dilation effect due to the flow expansion, which is consistent with experimental schlieren results in the literature [22].

- The analysis of the velocity field has confirmed that the hypothesis of self-similarity of the axial velocity also holds under reacting conditions, if the increase in spray width is accounted for.

This section intends to quantify the effects leading to the velocity increase observed in the reacting spray compared to the inert one, as well as an estimation of the air entrainment decrease due to heat release. Such analysis will be backed up by momentum conservation considerations, as well as by the 1D spray model.

\subsubsection{Analysis of the combustion-induced increase of axial velocity}

The previously observed effects can be quantified independently by means of the 1D spray model to evaluate how relevant they are for the final velocity distribution under reacting conditions. Conclusions should be valid, given the fact that the self-similarity of axial velocity holds, which is a core hypothesis in the 1D model. Figure 6 shows the onaxis velocity distribution (left) and radial spread (right) for both experiments and 1D model calculations at all three operating conditions. Under inert conditions, the model produces fair agreement of on-axis velocity with experiments, in a similar way to previous work [40]. When transitioning to reacting conditions, two assumptions are compared on the plot. First, a case where radial expansion has been inhibited (labelled as NOEXP) is included to evaluate the single effect of the combustion-induced density drop. In all three cases, this assumption results in a clear overprediction of on-axis velocity. Only when radial increase is considered by the model (cases labelled as DR), do velocity predictions fall close to actual measurements. Table 3 shows the increase in radial width for the $1 \%$ Radius as derived from the model compared to experimental values. For both experiments and model, radial expansion increases in the sequence $\mathrm{SA}<\mathrm{T} 2<\mathrm{EX}$, due to a longer ignition delay and lift-off, which results in igniting mass being shifted downstream and hence in a larger radial expansion. Although the trend is consistent for the model, the sensitivity is lower than in experiments. This can also be observed in Figure 6 (right). However, the magnitude of such divergences does not prevent from having a velocity prediction from the model which, given the simplicity, is more than reasonable.

A more fundamental analysis of combustion-induced velocity increase can be obtained from axial momentum conservation between the nozzle $(x=0)$ and a given axial position $x$ under the assumption of a steady axisymmetric spray. Following the derivation in [31], Appendix, with equations rearranged for a self-similar Gaussian function: 
$\dot{M}_{0}=\int_{0}^{R} \rho \cdot u^{2} \cdot 2 \pi r \cdot d r=u_{c l}^{2} \cdot 2 \pi \cdot R(x)^{2} \cdot \int_{0}^{1} \rho \cdot \exp \left[-2 \cdot 4.6 \cdot\left(\frac{r}{R}\right)^{2}\right] \cdot\left(\frac{r}{R}\right) \cdot d\left(\frac{r}{R}\right)$

where $\dot{M}_{0}$ stands for nozzle momentum flux, $\rho$ and $u$ stand for local time-averaged density and velocity, respectively, while $\mathrm{R}$ stands for the $1 \%$ radius, and thus the factor within the exponential function stems from $L N(1 / 0.01)=4.6$. By rearranging the previous expression, one can derive Equation (1) to solve $u_{c l}(x)$, the axial velocity on the spray axis $(r=0)$.

$u_{c l}(x)=\sqrt{\frac{1}{2 \pi} \frac{\dot{M}_{0}}{\int_{0}^{1} \rho \cdot \exp \left[-9.2 \cdot\left(\frac{r}{R}\right)^{2}\right] \cdot\left(\frac{r}{R}\right) \cdot d\left(\frac{r}{R}\right)}} \cdot \frac{1}{R(x)}$

The denominator includes the radially-integrated density profile, the calculation procedure for which is detailed in the Appendix section. This function can be obtained by means of the corresponding state relationship from the mixture fraction radial distribution, which depends on the mixture fraction on the axis $f_{c l}$ and the self-similar profile. By applying the previous equation to both the inert and reacting case, and assuming that $R(x)=R_{\text {inert }}(x)+\Delta R$ a relationship between the inert and reacting spray velocity is derived as shown in Equation (3):

$\frac{u_{c l, \text { reac }}(x)}{u_{\text {cl, inert }}(x)}=\sqrt{\frac{\int_{0}^{1} \rho_{\text {inert }} \cdot \exp \left[-9.2 \cdot\left(\frac{r}{R}\right)^{2}\right] \cdot\left(\frac{r}{R}\right) \cdot d\left(\frac{r}{R}\right)}{\int_{0}^{1} \rho_{\text {reac }} \cdot \exp \left[-9.2 \cdot\left(\frac{r}{R}\right)^{2}\right] \cdot\left(\frac{r}{R}\right) \cdot d\left(\frac{r}{R}\right)}} \cdot \frac{1}{1+\Delta R / R_{\text {inert }}(x)}$

The first term on the right handside of the equation includes the radially-integrated effect of density drop due to combustion on the velocity increase, while the second one quantifies the radial expansion. $f_{c l}$ can be estimated by assuming a Schmidt number equal to unity, wherefrom mixture fraction and axial velocity distributions are related by $f_{c l}=u_{c l} / u_{0}$, the latter parameter being shown in Figure 3 to be within 0.1 to 0.06 . If the radius increase term is neglected $(\Delta R=0)$, the integral can be estimated for the $f_{c l}$ values commented above, which renders a ratio equal to approximately 1.61 for SA and 1.68 for both T2 and EX. This is the factor of increase in the reacting velocity compared to the inert case observed in Figure 6 for the NOEXP cases. Furthermore, for the investigated conditions such values are similar to the factor $\sqrt{\frac{r h o_{a}}{r h o_{s t}}}$, which was used in [41] to account for the change in entrainment due to combustion compared to an inert spray when estimating the flame length in direct injection Diesel sprays. Only when including the corresponding radial increase is the prediction more accurate, as shown by the 1D spray model results on the plot. However, it must be noticed that the radial increase factor weight should decrease with axial distance to the nozzle (second term of Equation (3)), and therefore for long distances to the nozzle, the effect of the increase in radius will vanish.

\subsubsection{Analysis of ambient air entrainment}

A quantitative evaluation of air entrainment into the spray has been derived from the velocity field, together with the ambient density. For that purpose, the local entrainment rate is defined as:

$$
C_{e n t}=\frac{d \dot{m}}{d x} \frac{d_{e q}}{\dot{m}_{0}}
$$

This parameter is calculated by applying the following definition on the spray radial limit [9]:

$$
C_{e n t} \approx 2 \pi \rho_{a} r\left[-v_{r}+\tan (\theta) v_{x}\right] \cdot \frac{d_{e q}}{\dot{m}_{0}}
$$

where the spray limit has been chosen to be at the $1 \%$ velocity radius $r=R_{1 \%}$. Therefore, both velocity components $\left(v_{x}, v_{r}\right)$ and the local angle $\theta$ are evaluated at that particular location. While the analysis in previous sections has been based upon the velocity measurements within the spray, i.e. short laser pulse separation (section 2.2.1), for evaluation of entrainment the outer spray flow field is used.

Local entrainment rate results averaged in the 2800 to $4400 \mu$ s interval are presented in Figure 7. Only T2 and EX conditions have been included, due to the already commented limitations in the steady extent of SA condition as a 
consequence of the short injection duration. Starting with $\mathrm{T} 2$, one can find a relatively flat evolution of the inert entrainment rate fluctuating between 0.28 and 0.35 , in agreement with results in [9]. Lower values downstream 120 $d_{\text {eq }}$ are just an artefact of averaging a transient evolution, as the spray transient tip within accounts for around $50 \%$ of the spray tip penetration length [22]. When moving to reacting conditions, the general evolution drops below the inert one, with a fluctuation between 0.2 and 0.28 , i.e. an average $25 \%$ drop in entrainment. As for EX condition, the overall inert evolution is quite similar to $\mathrm{T} 2$, while the reacting one seems to be much more transient, with a flat evolution upstream and a drop around the LOL location. Further downstream, the entrainment rate is seen to increase up to similar values to the inert case.

Additional information on the global impact of combustion on air entrainment can be obtained from the 1D model in terms of total mass flux and local entrainment rate (Figure 8). The analysis has been done for T2 condition, but conclusions extend to the other two conditions, with the corresponding changes in LOL location. The plot shows the results for the three cases in Figure 6, namely the inert case and two reacting ones where radial expansion has been inhibited or is allowed. The evolution of all three cases is on top of each other upstream the lift-off length location, with an entrainment rate around 0.28 , which is within the average range of experiments (Figure 7). Downstream the lift-off length, the model shows a two-step evolution in the reacting case. In a first stage, entrainment rate is seen to drop dramatically to values as low as 0.05 , i.e. $82 \%$ lower than the inert case, from 60 to $85 \mathrm{~d}_{\text {eq }}$ in the expansion case, and from 60 to $100 \mathrm{~d}_{\text {eq }}$ in the no-expansion one. Downstream that location, entrainment seems to recover abruptly to values starting around 0.21 (i.e. $25 \%$ lower), with an asymptotical trend to the inert case. The inhibition of the radial expansion in the model results in a shift of the entrainment evolution away from the nozzle, but downstream $100 \mathrm{~d}_{\mathrm{eq}}$ the evolution is very similar for both modelling situations, consistently with the vanishing effect with axial distance of the radius increase term in Eq. 3.

The previous two zones in the entrainment downstream of the LOL can also be observed in Figure 6, where modelled on-axis velocity remains constant downstream the lift-off length location until a point where it starts dropping with axial distance. A similar evolution can be observed for the on-axis mixture fraction (not shown). This behaviour can be explained in terms of the underlying assumption on the integrated radial integrals (see Appendix), with a discontinuity at the lift-off location, which is translated into a spatial zone where on-axis velocity and mixture fraction remain constant, while entrainment drops to very low values. Once the mixture fraction drops below the lift-off value, the fully reacting spray behaviour is obtained, with the before mentioned $25 \%$ lower entrainment rate than the inert one. By comparing the case with and without radial expansion in Figure 6 and Figure 8, one can observe the abrupt increase in radial width at the lift-off length only modulates the initial drop in entrainment rate, while the general behaviour of the entrainment and on-axis velocity is the same.

Summing up, the previous results just downstream of the lift-off length are mainly due to the assumption of discontinuity of the radial integrals within the model (see Appendix), which is a simplification to model the adaptation of the flow from inert to reacting state. However, experiments also seem to indicate some evidences in this direction. On the one hand, the evolution of the experimental on-axis velocity compared to the modelled one in Figure 6 also hints at the possibility of existence of this initial heavy drop in entrainment around the lift-off location that tends to keep an approximately constant on-axis velocity. On the other hand, looking back at the experimental entrainment rate (Figure 7), results show a local minimum value at the LOL location, which is however less abrupt than in the modelling results. Further downstream, evolution for $\mathrm{T} 2$ reacting case is relatively similar to the inert one but at an approximately $25 \%$ lower value, although the limitations in the axial extent of the window prevents from the observation of the asymptotic trend towards the inert entrainment rate. It is interesting to note that the initial minimum of entrainment rate overlaps with the region between the $\mathrm{OH}^{*}$ and the disappearance of $355 \mathrm{~nm}$ LIF signal (Figure 5), which is consistent with the possibility that the entrainment reduction effect may be different around the lift-off length, more affected by low to high temperature transition, compared to other downstream locations, where the diffusion flame is fully stablished.

Further analysis can be made on the previous entrainment evolution by means of streamlines, which have been plotted for the EX case in Figure 9 with starting points at $r=20 \mathrm{~mm}$ and uniformly spaced in $x$ coordinate at the corresponding upper and lower boundaries. Both the external and internal velocity fields have been used to fully resolve the streamlines, with the frontier between both sets at the R5\% location. The analysis is only made for the EX 
condition, which shows a clear spatial separation between the inert and reacting condition within the measurement window.

The top plot shows only the PIV-derived information for both inert (left) and reacting (right) conditions. The inert case indicates an entrainment pattern almost perpendicular to the spray axis when the flow is outside of the spray radial extent, which later turns and becomes essentially axial within the limiting contour. For the reacting case, the overall pattern is similar, but some differences are worth being mentioned. First, the streamlines curvature is much more noticeable even out of the spray outer radius, and especially downstream of the LOL (60 $d_{\mathrm{eq}}$ ), where spray inert and reacting radii separate from each other. Estimations from schlieren measurements with ECN injectors indicate that the transient head vortex in a reacting spray can reach around $50 \%$ of the spray length, compared to just $30 \%$ for the inert case [22]. Therefore, the streamlines curvature in the reacting case evidences recirculation from the front non-steady spray head vortex. On the other hand, streamlines have been started from locations uniformly distributed in $\mathrm{x}$ direction at the bottom and top boundaries in both inert and reacting conditions. In the first case, the relative distance among such streamlines remains uniform for the whole set, being wider outside of the spray radius, and narrower when the trajectories become axial. However, no big difference is observed among different starting locations. For the reacting case, relative distance among trajectories remains uniform for those upstream of the LOL location. But downstream $60 \mathrm{~d}_{\mathrm{eq}}$, one can observe that such distance becomes wider. The latter point becomes more evident at the bottom plot of Figure 9, where the trajectories have been superimposed onto the LIF information. A reference PIV derived inert and reacting radius have also been included. The widening of the distance among trajectories is clearly coincident with the location of the $\mathrm{OH}$ signal, i.e. the high temperature diffusion flame front. This result hints at a decrease in entrainment rate in the reacting part, i.e. a reduced mass flow per unit area is dragged into the spray flow as a result of heat release.

The evolution of streamlines can help understand two additional issues from the analysis of entrainment in Figure 7. The first one is that upstream of the lift-off length the entrainment rate for the reacting case is already smaller than the inert one, for both $\mathrm{T} 2$ and EX conditions. The main reason for this result seems to be the change in flow direction for such locations. As already described, inert streamlines are almost perpendicular to the spray axis (i.e. almost zero axial velocity), while reacting ones exhibit a curvature with a negative component of the axial velocity that, according to equation (5), decreases entrainment. The consequence of this effect, however, is difficult to additionally observe in the experiments except for a slight increase in on-axis velocity for the reacting case at $60 \mathrm{~d}_{\mathrm{eq}}$ compared to the inert one (Figure 6).

On the other hand, the streamline curvature is also very noticeable for locations downstream $90 \mathrm{~d}_{\text {eq }}$, which may indicate that for EX condition the flow pattern under reacting conditions is largely affected by recirculation from the front vortex. This recirculation may create the increase in entrainment in the 80 to $100 \mathrm{~d}_{\mathrm{eq}}$ interval observed in Figure 7 (right), which may be more evident in such cases due to the long ignition delay and lift-off. There remains the question if this recirculation effect is solely due to the reacting flow dynamics, or it is also affected by the confinement of the spray within a constant volume chamber.

\subsubsection{Comparison with literature results}

Comparing the present study with the literature on Diesel sprays, local velocity under reacting conditions has been measured by Rhim and Farrell [16], although their analysis does not show a clear influence of heat release on the flow pattern. This is most probably due to the fact that the authors estimate a very long lift-off length for their conditions, which probably means that most of the measurements in the flame occur in the inert region. Given the absence of similar results in the literature, the present Diesel spray results can only be compared to those in momentum-controlled atmostpheric gas flames, for which detailed studies exist. The reference works by Han and Mungal [42], and Muñiz and Mungal [43] are used here, but it must be noted that in such experiments the jet is injected into a non-quiescent co-flow, with a velocity that is typically around $1.5 \%$ of the injection velocity, which results in lower entrainment already for the baseline inert cases [43]. A reduction in entrainment (up to 50\%) for the reacting flow compared to the inert one has been quantified in [42], and Muñiz and Mungal also observed 2.5 to 3 
times higher on-axis velocity compared to the inert flow [43]. Additionally, Tacina and Dahm [44] proposed a scaling law for turbulent non-buoyant reacting flows (for both axisymmetric and planar gas jets) in terms of an effective density, which collapsed experimental results from different authors. This effective density resulted in an increase of on-axis velocity between 2.8 and 3.3 for the different experimental data sources. On the other hand, Muñiz and Mungal [43] show that a Gaussian self-similar velocity profile can be considered as a good approximation for inert and reacting gas jets for $\mathrm{r}<\mathrm{R} 50 \%$, while some deviations exist at farther radial positions. Therefore, combustioninduced radial expansion for atmospheric gas jets has not been evidenced in the same way as for Diesel sprays, and depends on the width definition. The authors report a reduction in jet half width at R50\% for the reacting vs the inert cases, while they claim that the R1\% follows an opposite trend [43].

After the previous survey of results in the literature, the effect of combustion seems to be stronger for such atmospheric gas flames compared to the Diesel spray results reported here (around $25 \%$ overall reduction in entrainment, 50 to $60 \%$ increase in on-axis velocity), which agrees with the fact that the inert to reacting density ratio decreases with higher ambient gas temperature, and therefore a weaker inert-to-reacting transition should be expected under engine-like conditions.

\section{SUMMARY AND CONCLUSIONS}

An experimental analysis on the interaction between the spray flow under reacting conditions and the flame structure has been carried out. For that purpose, information from PIV and LIF techniques has been combined. Detailed flow evolution has evidenced the following changes in the reacting axial velocity field compared to the inert one:

- The transition from inert to reacting flow induces a density drop that increases local velocity in agreement with momentum conservation. For the present operating conditions a maximum 50 to $60 \%$ increase in local velocity has been found.

- Concurrent with the flow acceleration, a radial expansion effect due to the mixture transition from inert to reacting conditions occurs. This has been quantified in terms of a radius increase which, for the investigated conditions, ranges from 0.9 to $2.1 \mathrm{~mm}$.

- The hypothesis of self-similarity of axial velocity has been observed to hold both under inert and reacting conditions.

Previous evidences enabled the use of a 1D spray model under reacting conditions, which has confirmed the role of both density drop and radial expansion to adequately quantify the on-axis velocity evolution. Furthermore, this model has also enabled the quantification of the radial expansion and the decrease in entrainment rate due to combustion.

Modelling results suggest the existence of a first stronger drop in local entrainment rate at the lift-off length location followed by a milder evolution downstream, with an initially $25 \%$ lower entrainment rate in the reacting case that increases towards the inert one with increasing distance to the nozzle. Although the first drop is due to an imposed transition within the model from inert to reacting conditions at the lift-off length, experimental results also hint at the existence of these two zones, although the flow evolution is much smoother compared to the modelling ones.

When comparing the flow evolution with the flame structure, no strong effect of the chemical processes on the spray flow can be seen upstream the lift-off length, in spite of the fact that chemical activity is evidenced by formaldehyde LIF. Downstream the lift-off length, a clear influence of the high-temperature flame front, as defined by $\mathrm{OH}$ LIF, is seen on the flow, which results in an increase in PIV-derived flow width, as well as streamline separation correlating with the reduction in entrainment.

Based on both experiments and 1D modelling results, the main conclusions from the present work are as follows:

- Compared to the inert case, the flow evolution in the reacting one shows three changes 
- A first small reduction of entrainment rate upstream of the lift-off length, apparently due to the effect of large-scale flow recirculation, which has negligible influence on the velocity field within the spray.

- An important drop in entrainment rate at the lift-off location, where the flow is highly perturbed due to the transition from a fully inert state to a reacting one. The extent of this zone is around $20 d_{\text {eq }}$ for the investigated conditions.

- Further downstream, the flow is already adapted to the reacting environment, and the evolution is similar to the inert one but with a lower entrainment rate.

- Reacting velocity field downstream the lift-off length is the combined result of both density drop and radial expansion.

- Low temperature chemical activity is observed upstream of the lift-off length with little effect on flow evolution.

Further validation of the previous conclusions should be done in terms of detailed CFD calculations, which will enable a more accurate quantification of all the physical and chemical processes involved.

\section{ACKNOWLEDGEMENTS}

This work was carried out during a scientific visit period by J.M. Garcia-Oliver at IFPEN in 2015, which was funded by the Spanish Ministry of Education, Culture and Sport (Grant PRX14/00192). This study was partially funded by the Spanish Ministry of Economy and Competitiveness in the frame of the COMEFF (TRA2014-59483-R) project.

\section{REFERENCES}

[1] J. E. Dec, "A Conceptual Model of DI Diesel Combustion Based on Laser-Sheet Imaging*," 1997.

[2] G. Bruneaux, "Combustion structure of free and wall-impinging diesel jets by simultaneous laser-induced fluorescence of formaldehyde, poly-aromatic hydrocarbons, and hydroxides," Int. J. Engine Res. , vol. 9, no. 3, pp. 249-265, Jun. 2008.

[3] M. P. B. Musculus, P. C. Miles, and L. M. Pickett, "Conceptual models for partially premixed low-temperature diesel combustion," vol. 39, no. 2, pp. 246-283, 2013.

[4] Y. Shi, H.-W. Ge, and R. D. Reitz, Computational Optimization of Internal Combustion Engines. London: Springer London, 2011.

[5] "Engine Combustion Network Website." [Online]. Available: http://www.sandia.gov/ecn/ECNworkshop.php. [Accessed: 25-Jan-2016].

[6] J. D. Naber and D. L. Siebers, "Effect of gas density and vaporization on penetration and dispersion of Diesel sprays," SAE Pap. 960034, vol. 105, no. 412, pp. 82--111, 1996.

[7] L. M. Pickett, J. Manin, C. L. Genzale, D. L. Siebers, M. P. B. Musculus, and C. A. Idicheria, "Relationship Between Diesel Fuel Spray Vapor Penetration/Dispersion and Local Fuel Mixture Fraction," SAE Int. J. Engines, vol. 4, no. 1, pp. 764-799, 2011.

[8] G. E. Cossali, a. Geria, a. Coghe, and G. Brunello, "Effect of Gas Density and Temperature on Air Entrainment in a Transient Diesel Spray," SAE Pap. 960862, no. 412, 1996.

[9] W. E. Eagle, M. P. B. Musculus, L.-M. C. Malbec, and G. Bruneaux, "Measuring transient entrainment rates of a confined vaporizing diesel jet," in ILASS Americas, 26th Annual Conference on Liquid Atomization and Spray Systems, 2014, no. May.

[10] G. Bruneaux, M. Causse, and A. Omrane, "Air Entrainment in Diesel-Like Gas Jet by Simultaneous Flow Velocity and Fuel Concentration Measurements, Comparison of Free and Wall Impinging Jet Configurations," 
SAE Int. J. Engines, vol. 5, no. 2, pp. 76-93, 2011.

[11] B. Higgins and D. L. Siebers, "Measurement of the Flame Lift-Off Location on DI Diesel Sprays Using $\mathrm{OH}$ Chemiluminescence." SAE International , 2001.

[12] D. L. Siebers and B. Higgins, "Flame Lift-Off on Direct-Injection Diesel Sprays Under Quiescent Conditions." SAE International , 2001.

[13] L. M. Pickett, D. L. Siebers, and C. A. Idicheria, "Relationship Between Ignition Processes and the Lift-Off Length of Diesel Fuel Jets," SAE Tech. Pap., no. 724, p. , 2005.

[14] R. Venugopal and J. Abraham, "A Review of Fundamental Studies Relevant to Flame Lift-off in Diesel Jets," 2007.

[15] L. M. Pickett, S. Kook, H. Persson, and Ö. Andersson, "Diesel fuel jet lift-off stabilization in the presence of laser-induced plasma ignition," Proc. Combust. Inst., vol. 32 II, pp. 2793-2800, 2009.

[16] D.-R. Rhim and P. V Farrell, "Air Flow Surrounding Burning Transient Diesel Sprays," SAE Tech. Pap. 2002-012668, no. 724, 2002.

[17] H. Kobayashi, T. Kamimoto, and S. Matsuoka, "A Photographic and Thermodynamic Study of Diesel Combustion in a Rapid Compression Machine." SAE International, 1981.

[18] D. Rhim and P. V Farrell, “Evaporating Transient Diesel Sprays,” vol. 2002, no. 724, 2002.

[19] J. M. Desantes, J. V Pastor, J. M. García-Oliver, and F. J. Briceño, "An experimental analysis on the evolution of the transient tip penetration in reacting Diesel sprays," Combust. Flame, vol. 161, no. 8, pp. 2137-2150, 2014.

[20] L. M. Pickett and L. Hoogterp, "Fundamental Spray and Combustion Measurements of JP-8 at Diesel Conditions," SAE Int. J. Commer. Veh., vol. 1, no. 1, pp. 108-118, Apr. 2009.

[21] D. L. Siebers, "Recent Developments on Diesel Fuel Jets Under Quiescent Conditions," in Flow and Combustion in Reciprocating Engines, Berlin, Heidelberg: Springer Berlin Heidelberg, 2008, pp. 257-308.

[22] R. Payri, J. M. García-Oliver, T. Xuan, and M. Bardi, "A study on diesel spray tip penetration and radial expansion under reacting conditions," Appl. Therm. Eng., vol. 90, pp. 619-629, 2015.

[23] M. P. B. Musculus and K. Kattke, "Entrainment Waves in Diesel Jets," SAE Int. J. Engines, vol. 2, no. 1, pp. 2009-01-1355, Apr. 2009.

[24] B. W. Knox, C. L. Genzale, L. M. Pickett, J. M. Garcia-Oliver, and W. Vera-Tudela, "Combustion Recession after End of Injection in Diesel Sprays," SAE Int. J. Engines, vol. 8, no. 2, pp. 679-695, 2015.

[25] L.-M. Malbec, J. Egúsquiza, G. Bruneaux, and M. Meijer, "Characterization of a Set of ECN Spray A Injectors: Nozzle to Nozzle Variations and Effect on Spray Characteristics," SAE Int. J. Engines, vol. 6 (3), pp. 1642-1660, 2013.

[26] M. Meijer, L.-M. Malbec, G. Bruneaux, and Somers, "Engine Combustion Network: Spray A basic measurements and advanced diagnostics," in ICLASS 2012, 12th Triennial International Conference on Liquid Atomization and Spray Systems, 2012.

[27] N. Maes, M. Meijer, N. Dam, B. Somers, H. Baya Toda, G. Bruneaux, S. A. Skeen, L. M. Pickett, and J. Manin, "Characterization of Spray A flame structure for parametric variations in ECN constant-volume vessels using chemiluminescence and laser-induced fluorescence," Combust. Flame, vol. 174, pp. 138-151, 2016.

[28] F. P. Ricou and D. B. Spalding, "Measurements of entrainment by axisymmetrical turbulent jets," J. Fluid Mech., vol. 11, no. 1, p. 21, Aug. 1961.

[29] M. W. Thring and M. P. Newby, "Combustion length of enclosed turbulent jet flames," Symp. Combust., vol. 4, no. 1, pp. 789-796, Jan. 1953.

[30] J. M. Desantes, J. V Pastor, J. M. García-Oliver, and J. M. Pastor, "A 1D model for the description of mixingcontrolled reacting diesel sprays," Combust. Flame, vol. 156, no. 1, pp. 234-249, 2009. 
[31] J. V Pastor, J. Javier López, J. M. García, and J. M. Pastor, "A 1D model for the description of mixing-controlled inert diesel sprays," Fuel, vol. 87, no. 13-14, pp. 2871-2885, 2008.

[32] J. V Pastor, J. M. García-Oliver, J. M. Pastor, and W. Vera-Tudela, "One-dimensional diesel spray modeling of multicomponent fuels," At. Sprays, vol. 25, no. 6, pp. 485-517, 2015.

[33] X. Tauzia, A. Maiboom, and G. Ma, “A 1D Model for Diesel Sprays under Reacting Conditions,” 2015.

[34] B. W. Knox and C. L. Genzale, "Reduced-order numerical model for transient reacting diesel sprays with detailed kinetics," Int. J. Engine Res., 2015.

[35] A. L. Kastengren, F. Z. Tilocco, C. F. Powell, J. Manin, L. M. Pickett, R. Payri, and T. Bazyn, "Engine Combustion Network (ECN): Measurements of Nozzle Geometry and Hydraulic Behavior," At. Sprays, vol. 22, no. 12, pp. 1011-1052, 2012.

[36] C. A. Idicheria and L. M. Pickett, "Lift-off Location in a Diesel Jet," no. 724, pp. 776-790, 2016.

[37] S. A. Skeen, J. Manin, and L. M. Pickett, "Simultaneous formaldehyde PLIF and high-speed schlieren imaging for ignition visualization in high-pressure spray flames," Proc. Combust. Inst., vol. 35, no. 3, pp. 3167-3174, 2015.

[38] A. G. Gaydon, The Spectroscopy of Flames. Dordrecht: Springer Netherlands, 1974.

[39] J. O'Connor and M. Musculus, "Effects of exhaust gas recirculation and load on soot in a heavy-duty optical diesel engine with close-coupled post injections for high-efficiency combustion phasing," Int. J. Engine Res. , vol. 15, no. 4, pp. 421-443, Jun. 2014.

[40] R. Payri, J. P. Viera, H. Wang, and L.-M. Malbec, "Velocity field analysis of the high density, high pressure diesel spray," Int. J. Multiph. Flow, vol. 80, pp. 69-78, 2016.

[41] L. M. Pickett and D. L. Siebers, "Orifice diameter effects on diesel fuel jet flame structure," J. Eng. Gas Turbines Power-Transactions Asme, vol. 127, no. 1, pp. 187-196, 2005.

[42] D. Han and M. G. Mungal, "Direct measurement of entrainment in reacting/nonreacting turbulent jets," Combust. Flame, vol. 124, no. 3, pp. 370-386, 2001.

[43] L. Muñiz and M. . Mungal, "Effects of heat release and buoyancy on flow structure and entrainment in turbulent nonpremixed flames," Combust. Flame, vol. 126, no. 1-2, pp. 1402-1420, 2001.

[44] K. M. Tacina and W. J. A. Dahm, "Effects of Heat Release on Turbulent Shear Flows. Part I: A General Equivalence Principle for Nonbuoyant Flows and its Application to Turbulent Jet Flames.," J. Fluid Mech., vol. 415, pp. 23-44, 2000.

\section{Appendix: 1D model approach for the transition between the inert and reacting parts of the spray}

The transition between the inert and reacting part of the spray at the lift-off length is considered within the model as follows:

- In a first step, the model solves the inert and reacting state relationships (i.e. local density vs mixture fraction) in terms of pressure, fuel and air temperature and composition (Figure 2).

- In a second step, the density vs mixture fraction relationships are used for tabulation of the cross-sectional radial integrals needed in the conservation equations to convert the $2 \mathrm{D}$ into a $1 \mathrm{D}$ model (details can be found in [30], [31]), with the general definition in equation 6 for a Gaussian self-similar profile: 


$$
I N T=\int_{0}^{1} \rho \cdot \exp \left[-P \cdot 4.6 \cdot\left(\frac{r}{R}\right)^{2}\right] \cdot\left(\frac{r}{R}\right) \cdot d\left(\frac{r}{R}\right)
$$

where $\mathrm{R}$ stands for the $1 \%$ radius, and thus the factor within the exponential function stems from $\mathrm{LN}(1 / 0.01)=4.6$. From this general integral, $\mathrm{P}=2$ and $\mathrm{P}=1$ for momentum flux and mass flow rate, respectively. Some examples of these functions can be found in the derivations within Section 3.3 .1 (Eqs 1 to 3) for momentum flux. The role of these integrals is actually accounting for the accumulated effect of the radial density distribution. For a given state relationship and $\mathrm{P}$ value, they are only a function of centreline mixture fraction $f_{c l}$.

Taking into account that $f_{C l, L O L}$ is an input parameter to the model, the integral function is divided into two intervals. In the range $f_{c l}>f_{c l, L O L}$, which will represent locations upstream of the lift-off length, only the inert density is used. In the range $f_{c l} \leq f_{c l, L O L}$ (i.e. locations downstream the lift-off length), only the reacting case density is used for the integral. An example of such functions is shown in Figure 10;Error! No se encuentra el origen de la referencia.. The table is stored in discretized values of fcl between 0 and 1 (constant $\Delta f_{c l}$ steps), and therefore in the limit around $f_{c l, L O L}$ the integral is linearly interpolated. For the reported calculations $\Delta f_{c l}=0.001$, which is low enough so that a sharp transition exists and results are not sensitive to this discretization.

- Previous steps lead to the solution of the conservation equations, where the previous tabulated integrals are used. The algorithm solves $f_{c l}$ with no a priori knowledge or the range of the solution (whether $f_{c l}>f_{c l, L O L}$ or $\left.f_{c l} \leq f_{c l, L O L}\right)$. Results in section 3.3.1 show, however, that this approach produces a constant mixture fraction region at the lift-off length. 


\begin{tabular}{|l|ccccc|}
\hline CONDITION & $\begin{array}{c}\text { Ta } \\
{[\mathrm{K}]}\end{array}$ & $\begin{array}{c}\text { rhoa } \\
{\left[\mathrm{kg} / \mathrm{m}^{3}\right]}\end{array}$ & $\begin{array}{c}\text { XO2 } \\
{[\%]}\end{array}$ & $\begin{array}{c}\text { Pinj } \\
{[\mathrm{bar}]}\end{array}$ & $\begin{array}{c}\text { InjDuration } \\
{[\mu \mathrm{s}]}\end{array}$ \\
\hline SA & 900 & 22.8 & $15 / 0$ & 1500 & $\begin{array}{c}1500 \text { (PIV) } \\
/ 5000 \text { (LIF) }\end{array}$ \\
\hline T2 & 780 & 22.8 & $15 / 0$ & 1500 & 5000 \\
\hline EX & 780 & 14.8 & $15 / 0$ & 1500 & 5000 \\
\hline
\end{tabular}

Table 1 - Investigated operating conditions. ' $a$ ' stands for ambient conditions. XO2 is the mole fraction of oxygen in the ambient.

\begin{tabular}{|lcccc|}
\hline CONDITION & $\begin{array}{c}\text { ID } \\
{[\mu \mathrm{s}]}\end{array}$ & $\begin{array}{c}\mathrm{OH}^{*} \mathrm{LOL} \\
{[\mathrm{mm}]}\end{array}$ & $\phi_{\mathrm{cl}, \mathrm{LOL}}$ & $\begin{array}{c}\mathrm{d}_{\mathrm{eq}} \\
{[\mathrm{mm}]}\end{array}$ \\
\hline SA & 0.41 & 17.1 & 6.90 & 0.481 \\
\hline T2 & 0.77 & 24.6 & 2.824 & 0.481 \\
\hline EX & 1.19 & 39.5 & 2.404 & 0.597 \\
\hline
\end{tabular}

Table 2 - Combustion indicators for the investigated conditions. ID stands for Ignition Delay, OH*LOL for chemiluminiscence-derived lift-off length, $\phi_{c l}$ LoL for on-axis equivalence ratio at the lift-off length position and $d_{\text {eq }}$ for equivalent diameter (see the definition of this characteristic length within the text).

\begin{tabular}{|lccc|}
\hline CONDITION & $\begin{array}{c}\Delta \mathrm{R} 5 \% \\
{[\mathrm{~mm}]}\end{array}$ & $\begin{array}{c}\Delta \mathrm{R} 1 \% \\
{[\mathrm{~mm}]}\end{array}$ & $\begin{array}{c}\Delta \mathrm{R} 1 \% 1 \mathrm{D} \text { model } \\
{[\mathrm{mm}]}\end{array}$ \\
\hline SA & 0.70 & 0.87 & 1.19 \\
\hline T2 & 1.32 & 1.63 & 1.43 \\
\hline EX & 1.73 & 2.14 & 1.57 \\
\hline
\end{tabular}

Table 3 - Increase in radial width between inert and reacting velocity contours. R5\% is derived from PIV experiments, while R1\% is obta ined by correcting the $R 5 \%$ using the fact that for a Gaussian profile, $R 5 \% / R 1 \%=0.81$. Also the increase in radial width from the $1 D$ model is included. 


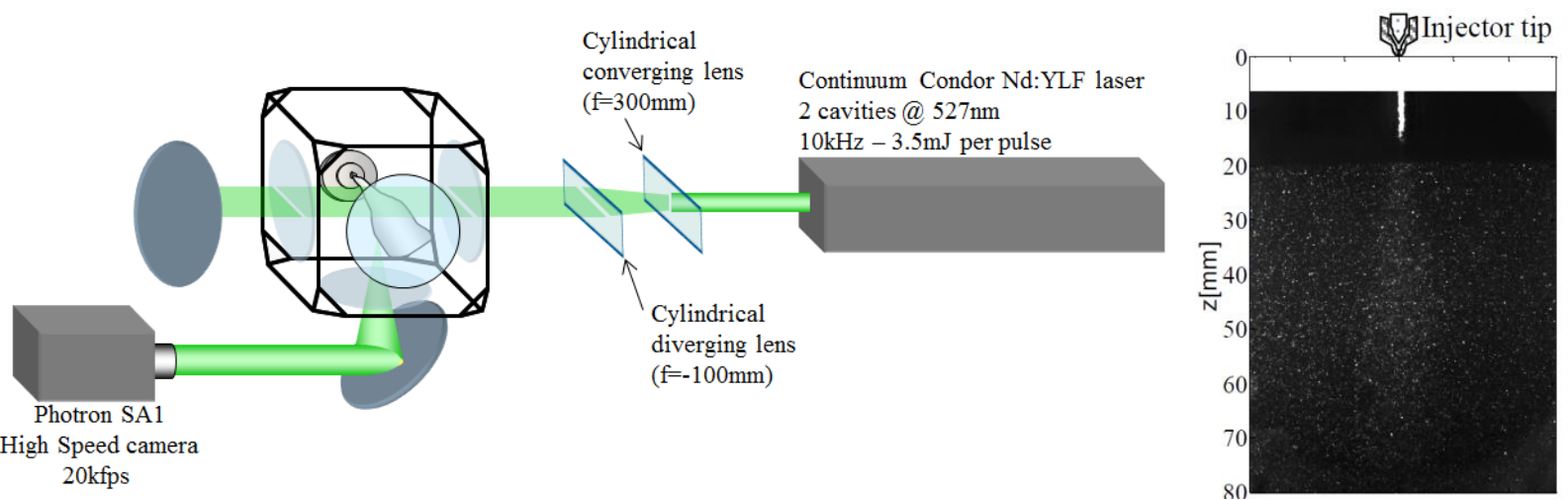

Figure 1 - Left: Experimental schematic, showing high-speed pulsed laser (right) directing a beam through sheet forming optics to the optical combustion chamber fitted with a diesel fuel injector (middle), and high-speed camera for PIV image acquisition (bottom-left). Right: Representative raw PIV image, acquired $1700 \mu$ s after the commanded start of injection. 


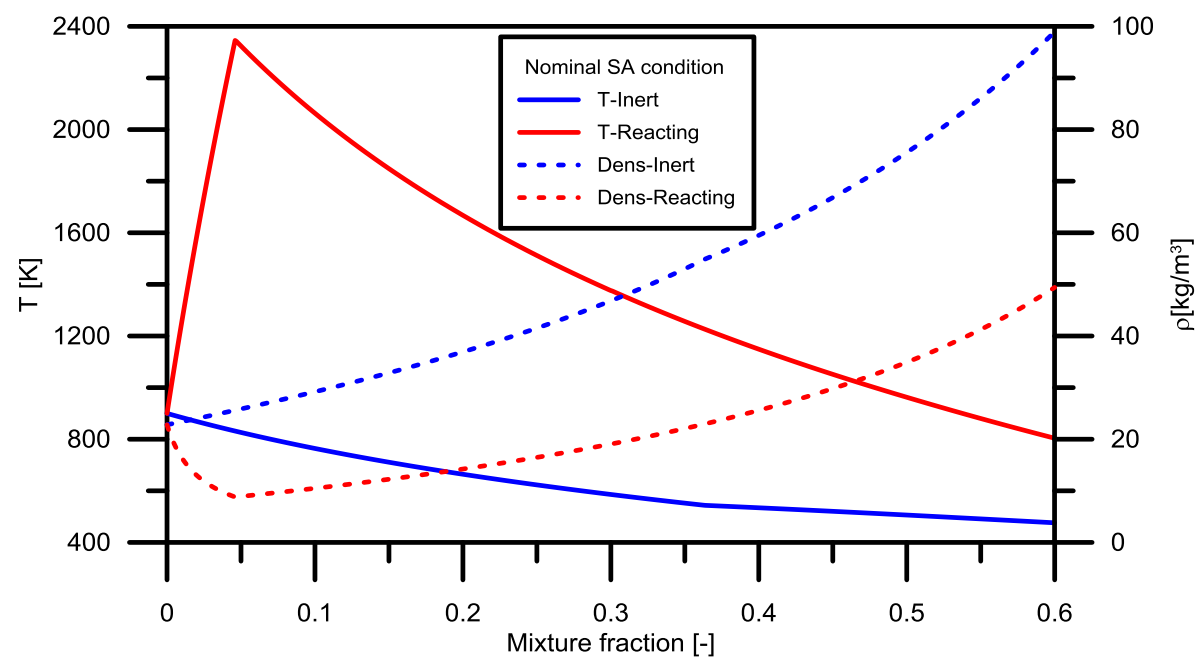

Figure 2 - State relationships for temperature and density at nominal Spray A conditions. P=6.07 MPa. N-dodecane at $363 \mathrm{~K}$ mixing with $15 \%$ O2 and 85\% N2 (mol) at 900K. Both inert and reacting results are shown. 

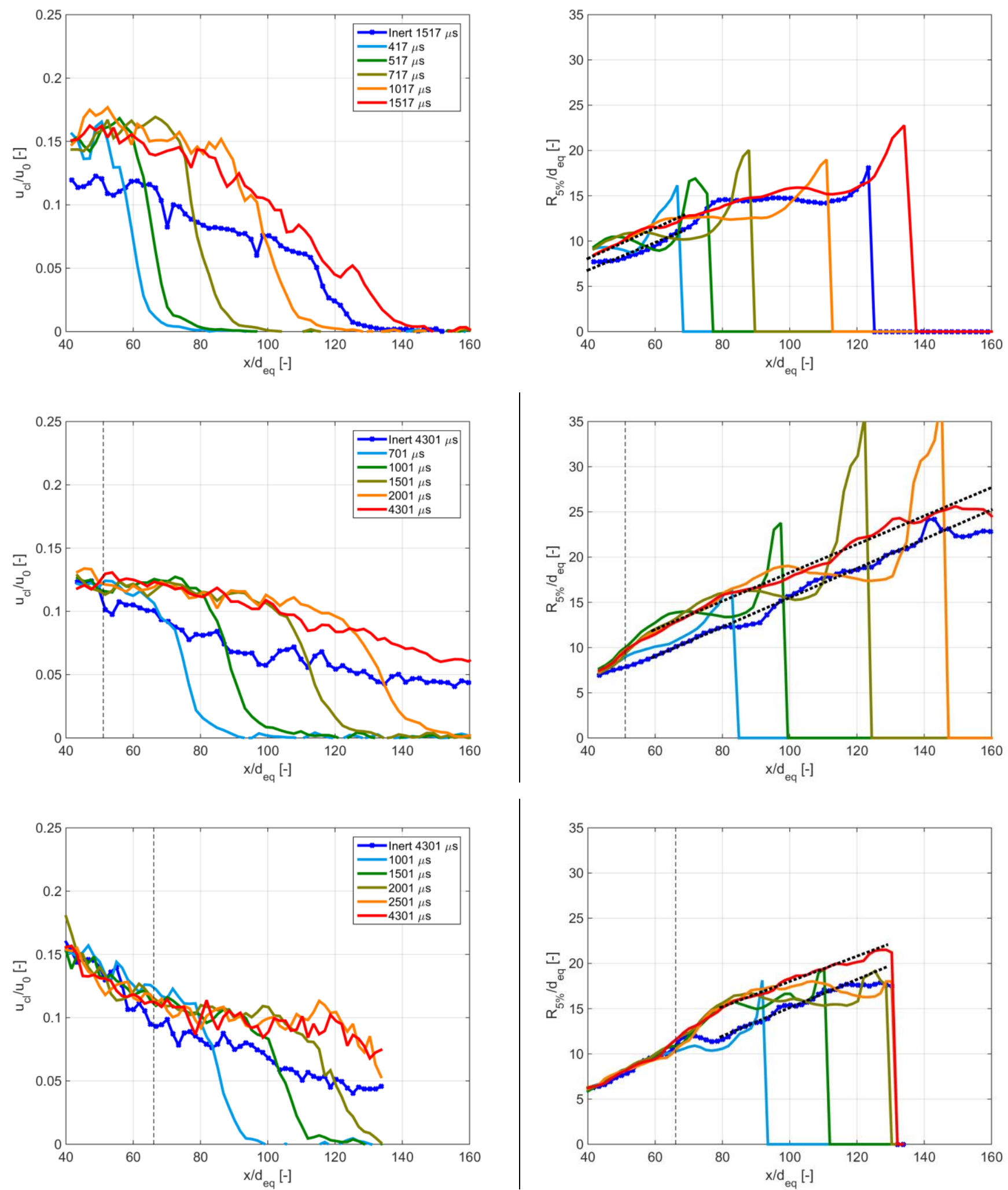

Figure 3 - Time development of average on-axis velocity (left) and axial velocity radius (right) under reacting condition. SA (top), T2 (middle) and EX (bottom). Vertical dashed lines indicate LOL location derived from $\mathrm{OH}^{*}$ visualization, except for SA condition, for which LOL/d eq $=35.5$, which falls outside of the PIV measurement region. Dotted lines show the linear fit to the radial contour for the latest time position. 

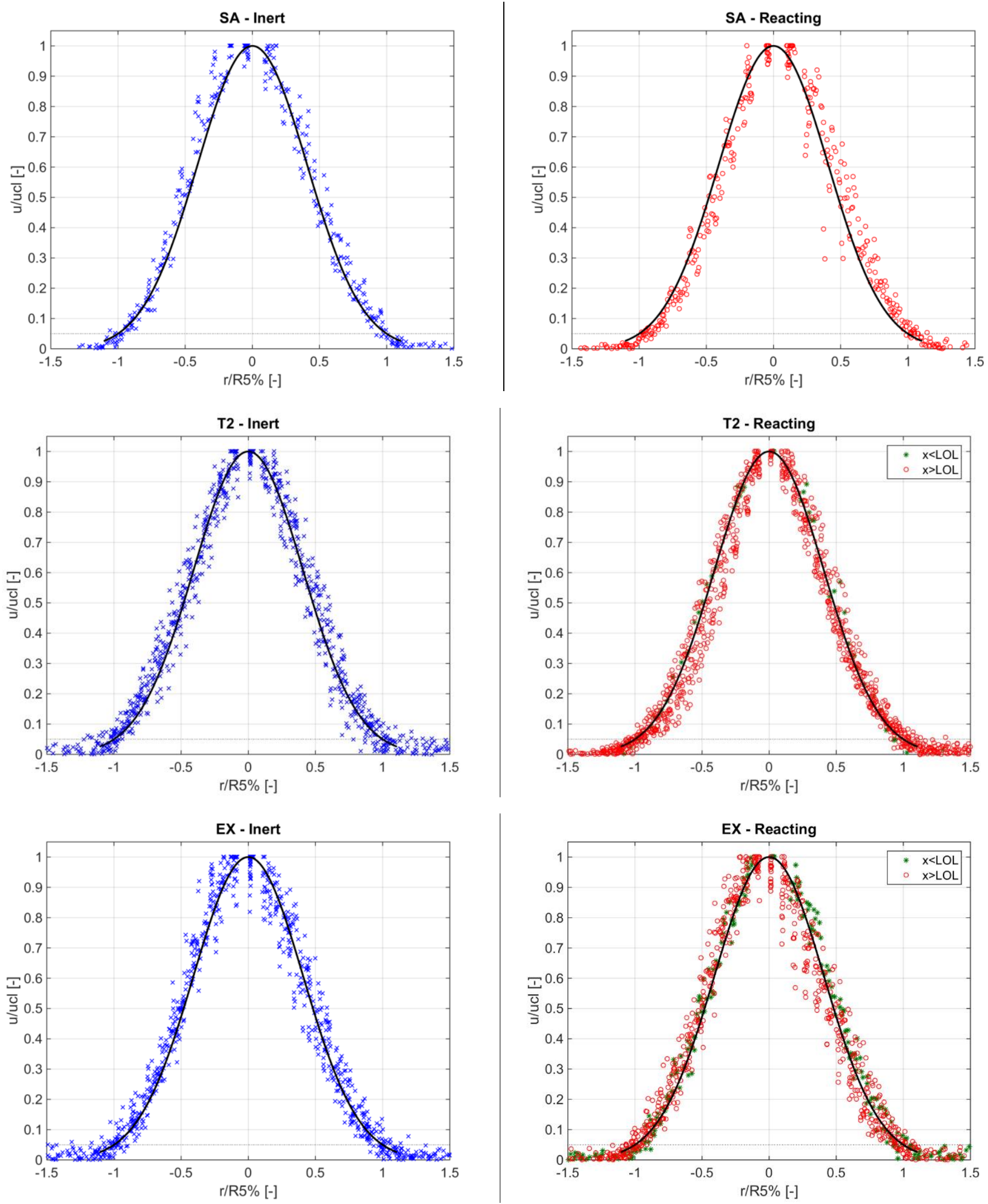

Figure 4 -Radial distribution of normalized velocity. Inert case (left), Reacting case (right). Solid line represents a Gaussian profile. SA (top) corresponds to $1401 \mu \mathrm{s}$, from $42 d_{\text {eq }}$ to $83 d_{\text {eq }}$ from the nozzle. T2 (middle) corresponds to $4301 \mu \mathrm{s}$, from $42 d_{e q}$ to $145 d_{e q}$ from the nozzle. EX (bottom) corresponds to $4301 \mu \mathrm{s}$, from $33 d_{\text {eq }}$ to $117 d_{\text {eq }}$ from the nozzle. For the T2 and EX reacting cases, a different marker has been used to separate locations upstream and downstream of LOL. This was not possible for SA due to the measuring position being downstream LOL. 

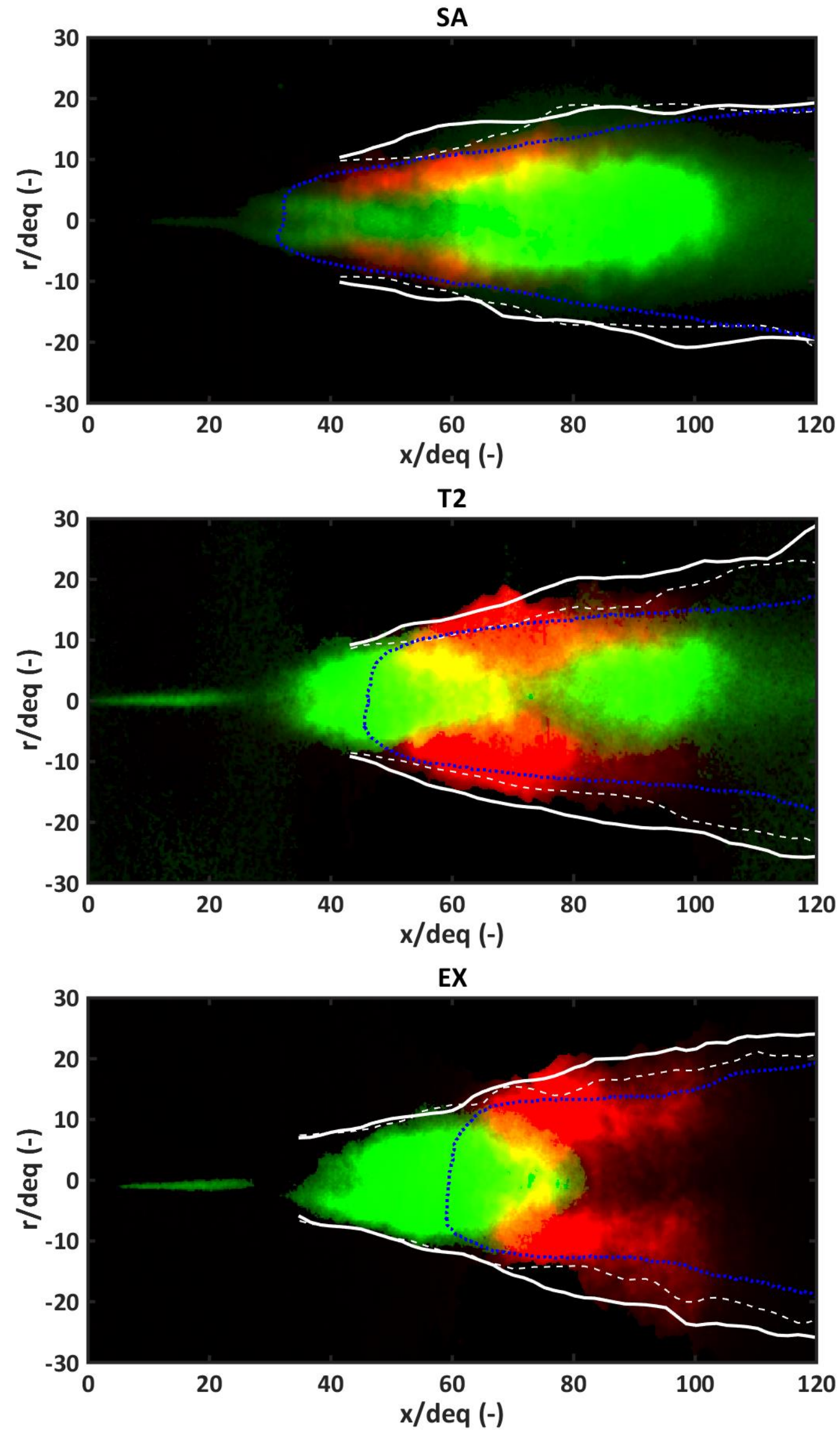

Figure 5 - Comparison of quasi-steady flame structure as derived from $\mathrm{OH}^{*}$ visualization, LIF techniques and PIV flow for the three operating conditions in the study. Green areas correspond to $355 \mathrm{~nm}$ LIF signal, while red ones are derived from OH LIF. Blue dotted contours indicate the extent of the $\mathrm{OH}^{*}$ chemiluminiscence signal. Overlaid contours show the PIV-derived 1\% radius from the axial velocity component for inert (dashed) and reacting (solid) cases. Note that for SA condition, PIV contours correspond to the short injection case, $t=1517 \mu \mathrm{s}$ 

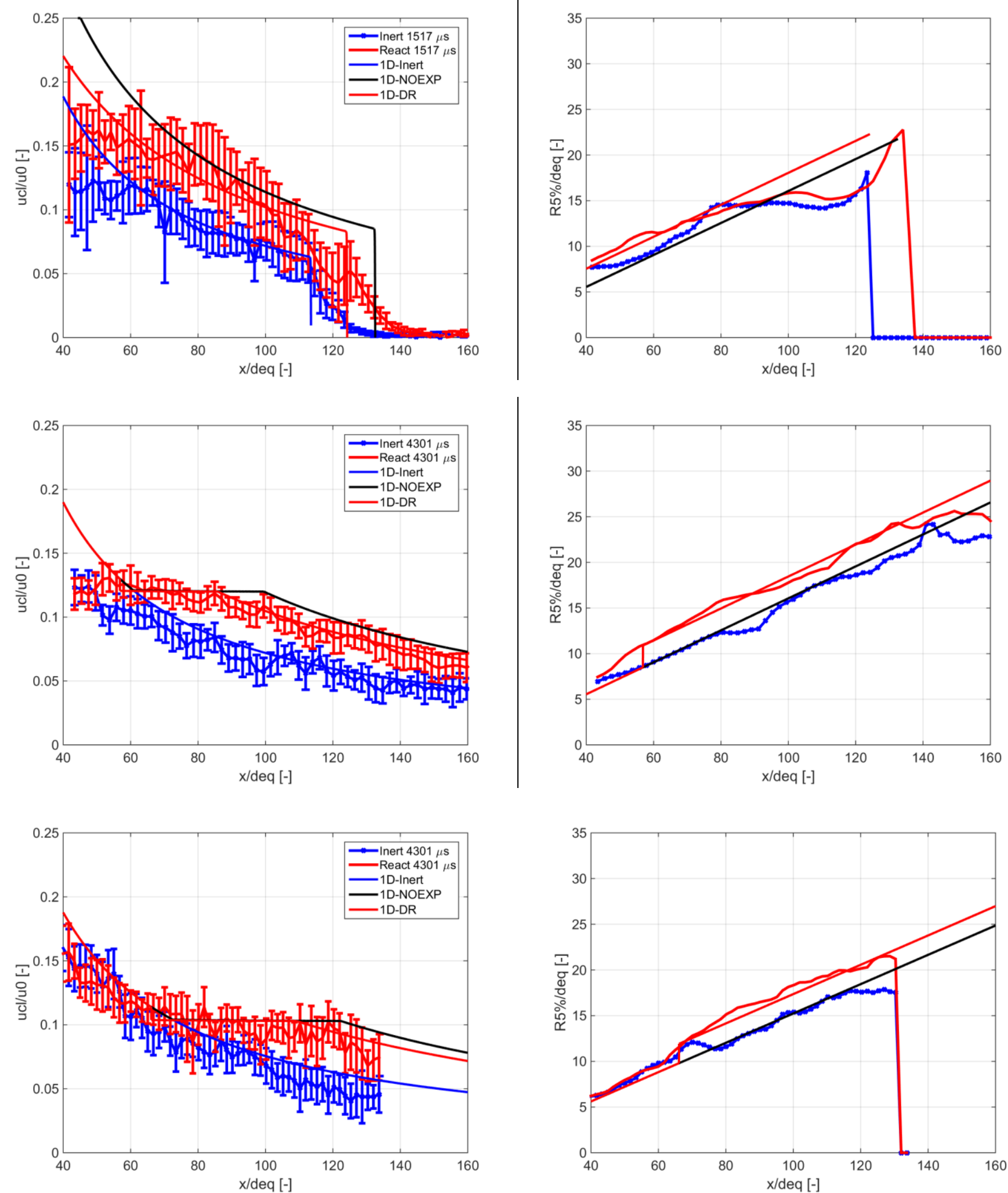

Figure 6 - On axis velocity distribution (left) and radial spread (right) for both experiments (Figure 3) and 1D model predictions. SA (top), T2 (middle) and EX (bottom). Error bars indicate measurement uncertainty. 

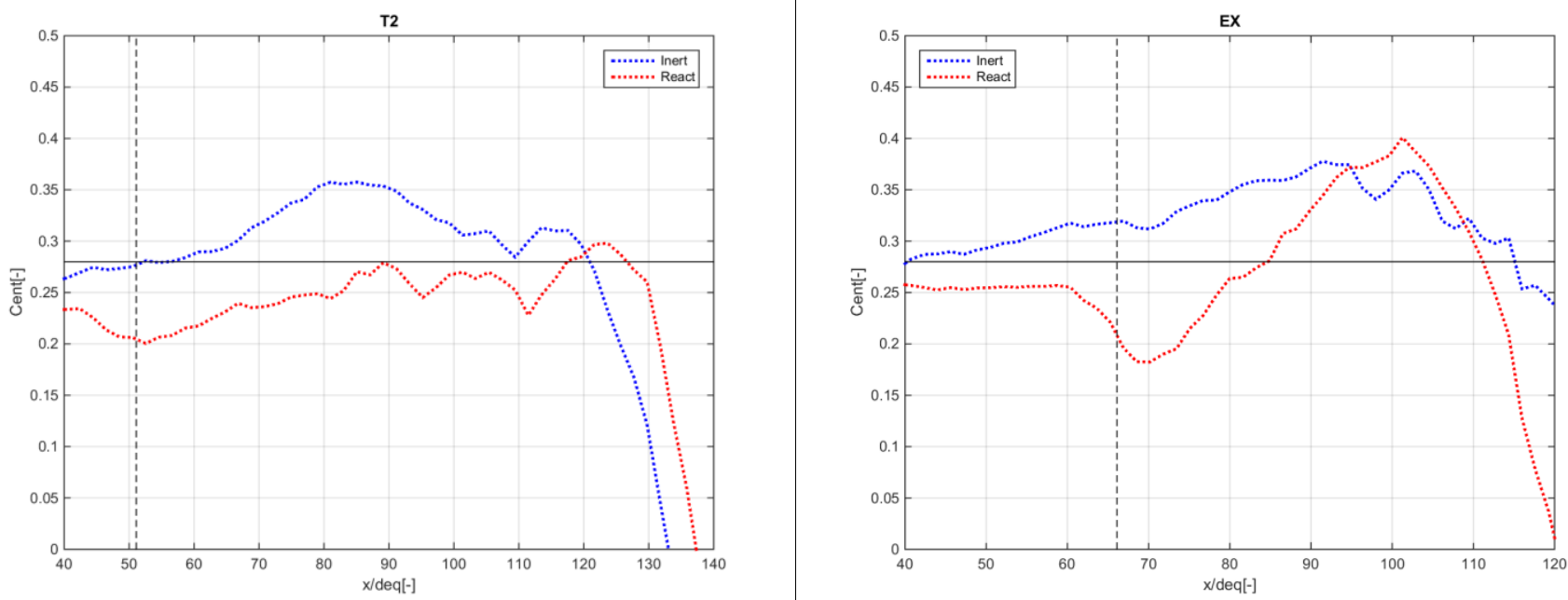

Figure 7 - Entrainment rate results for inert and reacting conditions averaged in the 2800 to $4400 \mu$ s after SOI. Condition T2(left) and EX (right).Vertical dashed line indicates the location of the $\mathrm{OH}^{*}$ derived lift-off length. Horizontal line indicates the 0.28 reference value derived from [9]. 

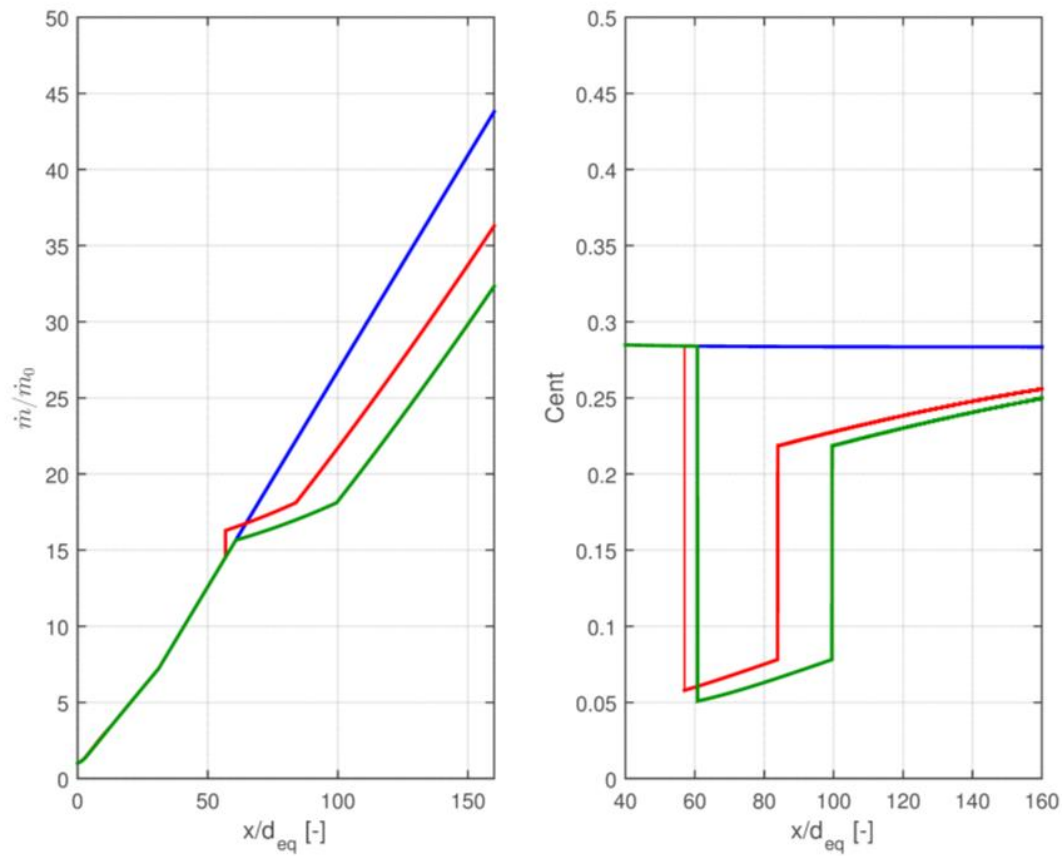

Figure 8-1D model-derived mass flow for $T 2$ case at $4300 \mu$ s (i.e. the same timing as in Figure 6, middle plot). 

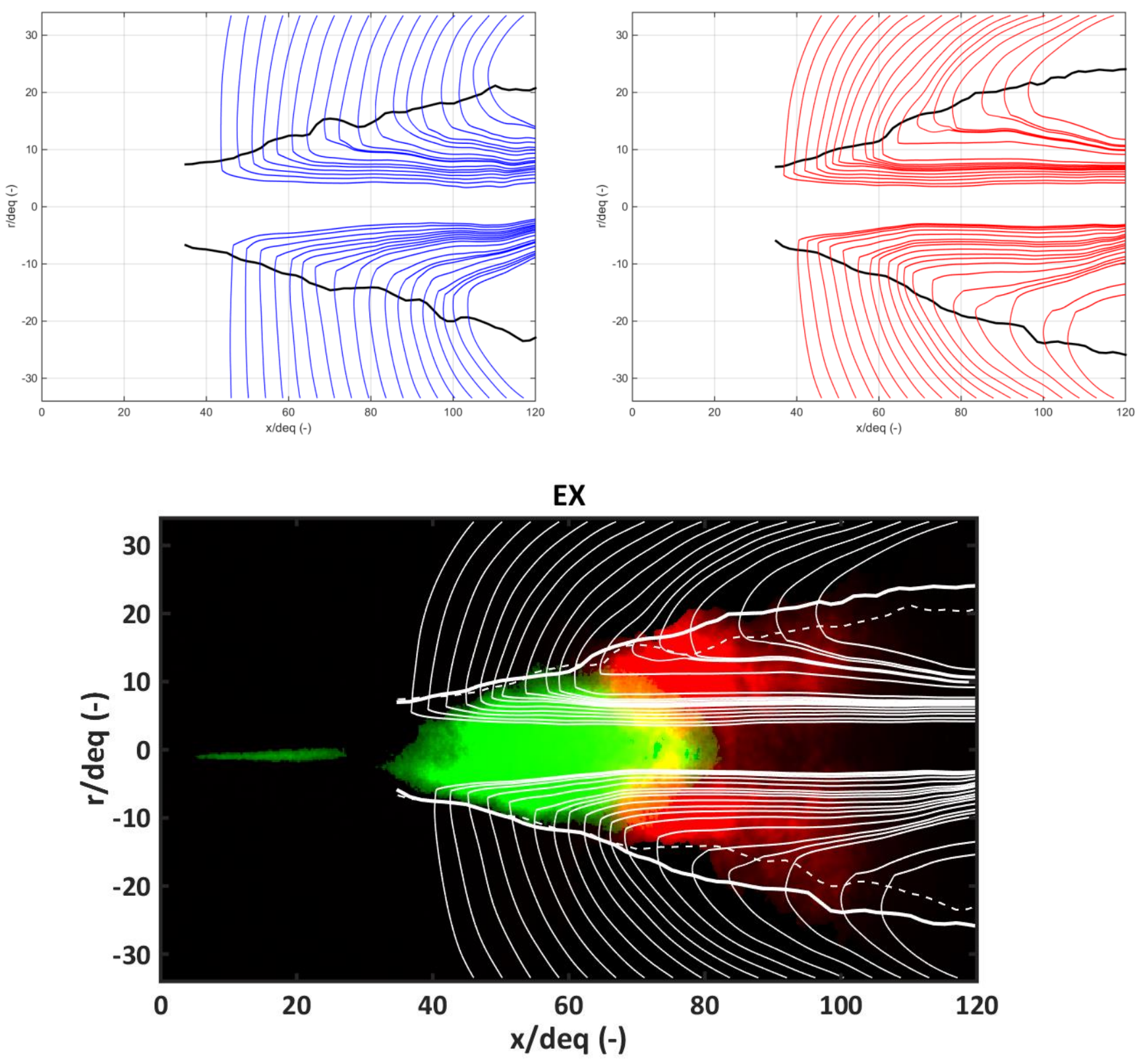

Figure 9 - Streamlines calculated from the outer flow for the EX condition. Top plot: streamlines for both inert (left) and reacting (right) conditions. Bottom plot: Streamlines for the reacting conditions superimposed onto the LIF-derived info as in Figure 5. 


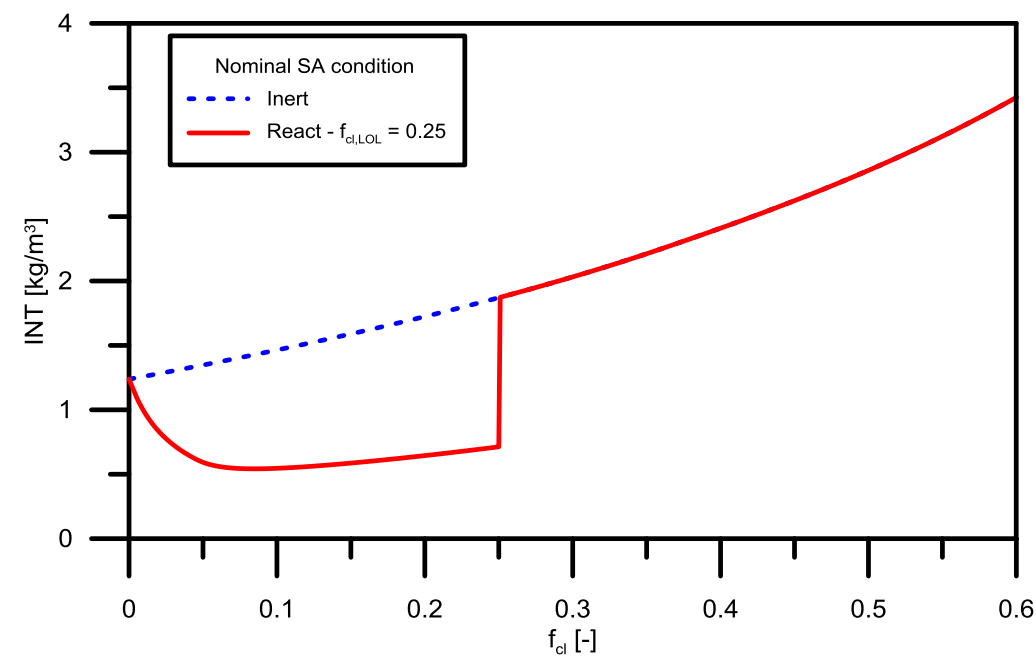

Figure 10 - Cross-sectional radial integral (Eq. 6) at nominal Spray A conditions, with $P=2$. Ambient pressure $=6.07 \mathrm{MPa}$. N-dodecane at $363 \mathrm{~K}$ mixing with 15\% 02 and $85 \%$ N2 (mol) at 900K. Both inert and reacting results are shown. 